\title{
Carbonic anhydrase inhibitors: Interactions of phenols with the 12 catalytically active mammalian isoforms (CA I-XIV)
}

\author{
Alessio Innocenti, Daniela Vullo, Andrea Scozzafava and Claudiu T. Supuran* \\ Università degli Studi di Firenze, Polo Scientifico, Laboratorio di Chimica Bioinorganica, Rm. 188, \\ Via della Lastruccia 3, 50019 Sesto Fiorentino (Florence), Italy
}

Received 6 December 2007; revised 17 January 2008; accepted 18 January 2008

Available online 26 January 2008

\begin{abstract}
The inhibition of the metalloenzyme carbonic anhydrase (CA, EC 4.2.1.1) with three phenols was investigated. Phenol was an effective CA I-IV, IX, XII and XIV inhibitor $\left(K_{\mathrm{I}} \mathrm{s}\right.$ of 2.7-11.5 $\left.\mu \mathrm{M}\right)$ and a less effective one against the other isoforms, CA VA, VB, VI, VII, and XIII $\left(K_{\mathrm{I}} \mathrm{S}\right.$ of $\left.208-710 \mu \mathrm{M}\right)$. 3,5-Difluorophenol was an effective inhibitor of CA III, IV, IX, and XIV $\left(K_{\mathrm{I}} \mathrm{S}\right.$ of $\left.0.71-10.7 \mu \mathrm{M}\right)$ being a weaker one for CA I, II, VA, VB, VI, VII, XII, and XIII $\left(K_{\mathrm{I}} \mathrm{s}\right.$ of $\left.33.9-163 \mu \mathrm{M}\right)$. Clioquinol $(5-$ chloro-7-iodo-8-quinolinol) was the best phenol inhibitor against all isozymes, with inhibition constants in the range of 3.3$16.0 \mu \mathrm{M}$. These data prove that the phenol $\mathrm{OH}$ moiety can be considered as a new 'zinc-water binding group' for the design of CA inhibitors possessing a different inhibition mechanism as compared to the classical sulfonamide inhibitors that bind the metal ion within the active site cavity.
\end{abstract}

(c) 2008 Elsevier Ltd. All rights reserved.

Phenol was shown to be the only competitive inhibitor with $\mathrm{CO}_{2}$ as substrate for the main isoform of carbonic anhydrase (CA, EC 4.2.1.1), that is, human CA II (hCA II) by Lindskog's group. ${ }^{1}$ Indeed, the other two major classes of CA inhibitors (CAIs), the metal-complexing anions, and the unsubstituted sulfonamides and their bioisosteres (i.e., the sulfamates, sulfamides, and related compounds), bind to the $\mathrm{Zn}$ (II) ion of these enzymes either by substituting the non-protein zinc ligand to generate a tetrahedral adduct or by addition to the metal coordination sphere, generating trigonal-bipyramidal species, and are non-competitive inhibitors with $\mathrm{CO}_{2}$ as substrate (Fig. $1 \mathrm{~A}$ and $\mathrm{B}){ }^{2-7} \mathrm{As} \mathrm{CO}_{2}$ is a very simple, small, and gaseous molecule, it is rather difficult to design transition state analogues or alternative substrates for understanding the binding mode of the physiologic substrate $-\mathrm{CO}_{2}-$ within the active sites of these ubiquitous enzymes, which catalyze one of the simplest physiological reaction, the interconversion between carbon dioxide and bicarbonate. ${ }^{1-7}$ Cyanamide $\left(\mathrm{H}_{2} \mathrm{NCN}\right.$, or $\mathrm{HN}=\mathrm{C}=\mathrm{NH}$ ), a molecule isostructural and isoelectronic with $\mathrm{CO}_{2}$ was investigated by spectroscopy and $\mathrm{X}$-ray crystallography as a CAI, being shown that it acts

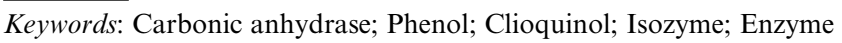
inhibitor; Inhibition mechanism.

* Corresponding author. Tel.: +39 055 4573005; fax: +39 055

4573385; e-mail: claudiu.supuran@unifi.it as a suicide inhibitor, leading to the formation of ureate $\left(\mathrm{H}_{2} \mathrm{NCONH}^{-}\right)$by hydration with the zinc-bound water molecule/hydroxide ion from the enzyme active site, which remains thereafter steadily bound to the metal ion within the enzyme cavity. ${ }^{8} \mathrm{~A}$ subsequent cryo-crystallographic X-ray study ${ }^{9}$ (done at $-80^{\circ} \mathrm{C}$ for slowing down the hydration of cyanamide to urea) evidenced the transition state for cyanamide hydration by CA II, with the substrate/inhibitor molecule $\left(\mathrm{H}_{2} \mathrm{NCN}\right)$, being found in the neighborhood of the metal ion, probably in a position slightly different, but mimicking the binding of carbon dioxide. ${ }^{9}$ In a very elegant study, Christianson's group also reported the X-ray structure for the adduct of hCA II with phenol, ${ }^{10}$ showing indeed this inhibitor to bind in a completely unprecedented manner, with its $\mathrm{OH}$ moiety hydrogen-bonded to the zinc-bound water/hydroxide ion of the enzyme (the experiments were performed at $\mathrm{pH} 10$ ) as well as to the $\mathrm{NH}$ amide of Thr199 (an amino acid conserved in all $\alpha$-CAs). Furthermore, the phenyl moiety of phenol was found to lay in the hydrophobic part of the hCA II active site, where it is presumed that $\mathrm{CO}_{2}$ binds in the precatalytic complex (Fig. 1C), explaining thus the behavior of unique $\mathrm{CO}_{2}$ competitive inhibitor of this compound. ${ }^{10}$

Sulfonamide CAIs, such as acetazolamide 1, methazolamide $\mathbf{2}$, and ethoxzolamide $\mathbf{3}$ among others, are clinically used drugs as diuretics, antiglaucoma, or anticonvulsant 

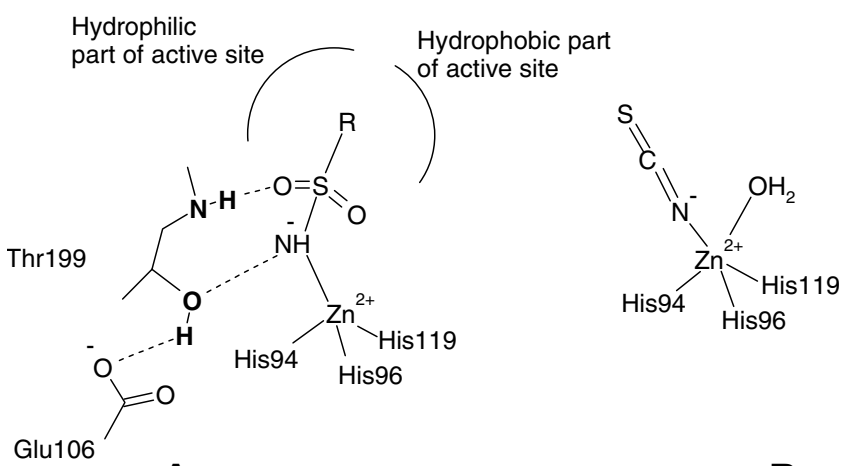

A

B

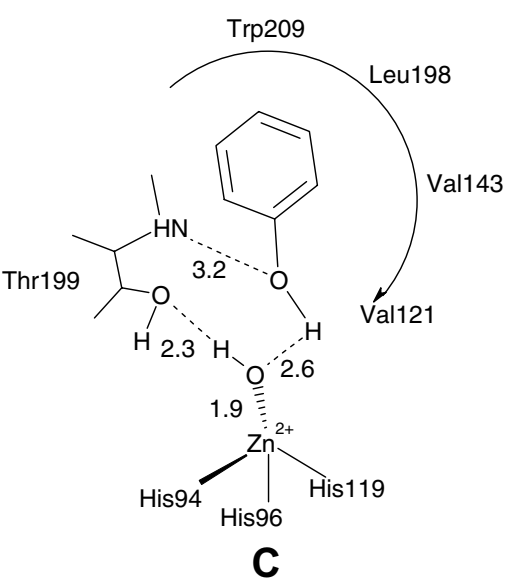

Figure 1. Schematic representation for interactions of CAIs with the CA active site: (A) sulfonamide inhibitors; (B) inorganic anion inhibitor (thiocyanate); (C) phenol. The interaction in which phenol participates when bound to the hCA II active site is shown in detail (figures represent distances in $\AA$; hydrogen bonds are represented as dashed lines).

agents for a long period, ${ }^{2-7}$ whereas more recent drug design studies evidenced some other CAIs belonging to the sulfonamide or sulfamate classes as molecules of interest for developing novel therapies for obesity ${ }^{11}$ and cancer $^{2,5,12-15}$ based on selective inhibition of CA isozymes involved in such pathologies, among the 16 presently known $\alpha$-CAs in vertebrates..$^{2-7,11-15}$ Thus, in the search of non-sulfonamide CAIs belonging to different classes of compounds, and possibly showing selectivity for isozymes of medicinal chemistry interest, ${ }^{2-7}$ we decided to reexamine phenols as CAIs, for at least two reasons: (i) phenol $\mathbf{4}$ has been investigated only for the inhibition of isozyme II by Lindskog et al. ${ }^{1}$ (and obviously subsequently by Christianson's group) ${ }^{10}$ Thus, all other isoforms discovered after 1982, that is, CA III-CA XIV (but also CA I, known at that time), have not been studied for their interaction with this class of inhibitor, which shows a binding mechanism completely different from that of the sulfonamide and inorganic anion inhibitors (see Fig. 1); (ii) various phenols, such as for example clioquinol (5-chloro-7-iodo-8-quinolinol), have applications as pharmacological agents. ${ }^{16-20}$ Indeed, clioquinol was used already in the 1960s as an intestinal disinfectant, ${ }^{16}$ for the treatment of Entamoeba histolytica infection, ${ }^{16}$ as an antifunga ${ }^{17}$ or antiviral agent. ${ }^{18}$ However, a sensory neuropathy with peculiar clinical and histopathological features which began to appear in Japan around 1960, denominated thereafter subacute myelo-optico-neuropathy (SMON), was demonstrated to be provoked by the wide use of high dosages of clioquinol. ${ }^{19}$ This led to the withdrawal of the drug from wide clinical use as an antibiotic, ${ }^{19}$ but more recently, interest in this phenol has been greatly revived by the report of its potential use to treat Alzheimer's ${ }^{20}$ and Huntington's disease ${ }^{21}$ (at concentrations much lower than those provoking SMON) ${ }^{20,21}$ Furthermore, there are also literature data suggesting an antitumor effect of this drug. ${ }^{22}$ The mechanisms by which the drug acts as an anti-Alzheimer's/Huntington's diseases agent seem to be related to its ability to act as a zinc and copper ions chelator that can dissolve amyloid deposits and show a net clinical benefit in the treatment of these degenerative diseases. ${ }^{20,21}$ On the other hand, it has been demonstrated that clioquinol increases functional hypoxia-inducible factor $1-\alpha$ (HIF-1 $\alpha$ ) protein, leading to increased expression of its target genes, such as vascular endothelial growth factors, erythropoietin, and the tumor-associated CA isoforms CA IX and XII. ${ }^{5 a, 22 c, 23}$ All these recent developments prompted us to investigate the interactions of three phenols, that is, the simple phenol 4, its 3,5-difluoro analogue 5 as well as clioquinol $\mathbf{6}$, with all the catalytically active mammalian $\alpha$-CA isozymes, that is, CA I, II, III, IV, VA, VB, VI, VII, IX, XII, XIII, and XIV.

Inhibition data against the above mentioned CA isozymes with phenols 4-6 (as well as sulfonamides 1-3, as standards, for comparison), are shown in Table 1, and they were obtained at $\mathrm{pH} 7.4$ in $10 \mathrm{mM}$ Hepes buffer, at $25^{\circ} \mathrm{C}$ by a stopped-flow assay monitoring the

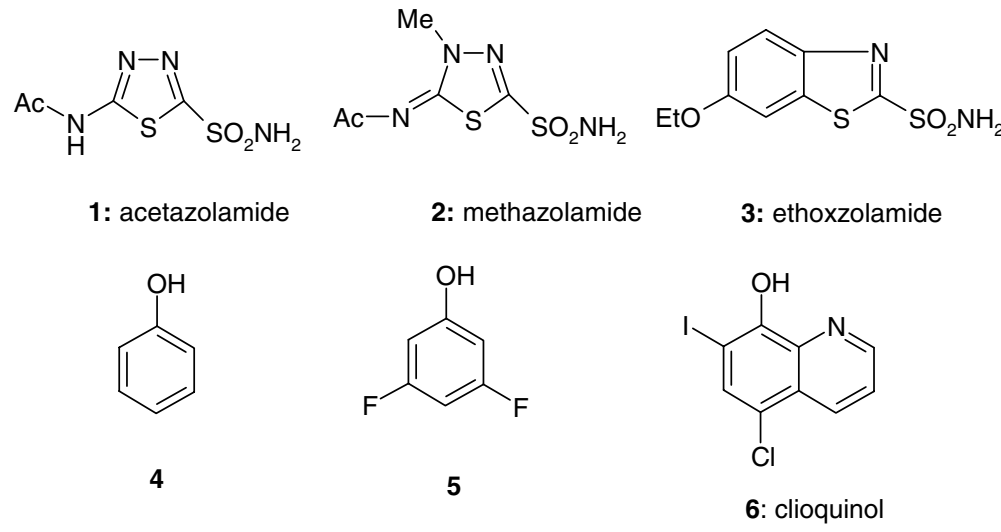


Table 1. Inhibition data with the clinically used sulfonamides acetazolamide $\mathbf{1}$, methazolamide $\mathbf{2}$, ethoxzolamide $\mathbf{3}$, as well as phenol $\mathbf{4}$, 3,5-difluorophenol $\mathbf{5}$, and clioquinol $\mathbf{6}$, against CA isozymes I-XIV by a stopped-flow technique monitoring the $\mathrm{CO}_{2}$ hydration reaction, at $25^{\circ} \mathrm{C}$ and $\mathrm{pH} 7.4^{24}$

\begin{tabular}{lllllll}
\hline Isozyme $^{*}$ & \multicolumn{7}{c}{$K_{\mathrm{I}}^{* *}(\mu \mathrm{M})$} \\
\cline { 2 - 7 } & $\mathbf{1}$ & $\mathbf{2}$ & $\mathbf{3}$ & $\mathbf{4}^{\mathrm{a}}$ & $\mathbf{5}^{\mathrm{a}}$ & $\mathbf{6}^{\mathrm{a}}$ \\
\hline hCA I $^{\mathrm{b}}$ & 0.250 & 0.050 & 0.025 & 10.2 & 38.8 & 6.6 \\
hCA II $^{\mathrm{b}}$ & 0.012 & 0.014 & 0.008 & 5.5 & 33.9 & 6.5 \\
hCA III $^{\mathrm{b}}$ & 200 & 710 & 1100 & 2.7 & 0.71 & 3.3 \\
hCA IV $^{\mathrm{b}}$ & 0.074 & 6.20 & 0.093 & 9.5 & 10.7 & 5.4 \\
hCA VA $^{\mathrm{b}}$ & 0.063 & 0.065 & 0.025 & 218 & 65.0 & 8.3 \\
hCA VB $^{\mathrm{b}}$ & 0.054 & 0.062 & 0.019 & 543 & 98.4 & $\mathrm{nt}$ \\
hCA VI $^{\mathrm{b}}$ & 0.011 & 0.010 & 0.043 & 208 & 82.6 & 5.3 \\
hCA VII $^{\mathrm{b}}$ & 0.0025 & 0.0021 & 0.0008 & 710 & 163 & 16.0 \\
hCA IX $^{\mathrm{c}}$ & 0.025 & 0.027 & 0.034 & 8.8 & 9.4 & 5.6 \\
hCA XII $^{\mathrm{c}}$ & 0.0057 & 0.0034 & 0.022 & 9.2 & 70.2 & 8.1 \\
mCA XIII $^{\mathrm{b}}$ & 0.017 & 0.019 & $0.050^{\mathrm{a}}$ & 697 & 84.2 & 4.9 \\
hCA XIV $^{\mathrm{b}}$ & 0.041 & 0.043 & 0.025 & 11.5 & 10.6 & 5.0 \\
\hline
\end{tabular}

${ }^{a}$ New data reported here for the first time.

${ }^{\mathrm{b}}$ Full length, recombinant enzyme.

${ }^{\mathrm{c}}$ Catalytic domain.

* $\mathrm{h}$, human; m, murine isozyme; $\mathrm{nt}$, not tested.

** Errors in the range of $\pm 5 \%$ of the reported data from three different assays.

$\mathrm{CO}_{2}$ hydration reaction. ${ }^{24}$ The following should be noted regarding the inhibition of these mammalian $\alpha$ CA isozymes with phenols 4-6: (i) phenol 4 acts as an effective, low micromolar inhibitor of isozymes hCA I, II, III, IV, IX, XII, and XIV, with inhibition constants in the range of 2.7-11.5 $\mu \mathrm{M}$, being a less effective inhibitor (in the millimolar range) of hCA VA, VB, VI, VII, and $\mathrm{mCA}$ XIII $\left(K_{\mathrm{I}} \mathrm{S}\right.$ of $\left.208-710 \mu \mathrm{M}\right)$. It should be mentioned that Lindskog's group reported a $K_{\mathrm{I}}$ of $10 \mathrm{mM}$ for the inhibition of hCA II with phenol, but their measurements were done at $\mathrm{pH} 9$ and in the presence of $50 \mathrm{mM}$ of 1,2-dimethylimidazole as buffer. ${ }^{1}$ However, it is now known that imidazoles and related compounds are inappropriate to be used as buffers in CA assays, as they act as potent activators of many CA isoforms (such as CA I, II, IV, VA, VB, VI, VII, XII, and XIV among others), ${ }^{25-27}$ intervening in the proton transfer processes between the active site and the reaction medium. ${ }^{28,29}$ Such processes lead to a competition between the binding of the inhibitor (in this case phenol) and the activator (imidazole derivative) within the enzyme active site, and explain the much higher $K_{\mathrm{I}}$ obtained in the preceding study ${ }^{1}$ as compared to this one, in which a non-activating buffer, which does not bind within the enzyme active site (i.e., Hepes) ${ }^{24}$ has been employed; (ii) 3,5difluorophenol 5, which is more acidic than the unsubstituted derivative $\mathbf{4}$, has been investigated as a CAI in order to understand whether the $\mathrm{p} K_{\mathrm{a}}$ of the $\mathrm{OH}$ phenolic moiety is an important parameter for the binding of such an inhibitor to the enzyme active site. In fact, sulfonamides (and their isosteres) bind to CA in deprotonated form, as anions (as also shown in Fig. 1A), whereas the protonation state of phenol $\mathbf{4}$ bound to hCA II (as reported by Nair et al.) ${ }^{10}$ is less clear. Apparently the inhibitor $\mathbf{4}$ is bound in neutral form to the enzyme, as represented schematically in Figure 1B. This seems to be confirmed also by the inhibition data of
Table 1, which show 5 to be a potent inhibitor of isozymes hCA III, IV, IX and XIV (inhibition constants in the range of $0.71-10.7 \mu \mathrm{M}$ ), a weaker one against hCA I, II, VA and XII $\left(K_{\mathrm{I}} \mathrm{s}\right.$ in the range of 33.9$70.2 \mu \mathrm{M})$, and an even weaker one against hCA VB, VI, VII and mCA XIII $\left(K_{\mathrm{I}} \mathrm{s}\right.$ in the range of 82.6$163 \mu \mathrm{M}$ ). In fact, there are isozymes (such as hCA I, II, IX and XII), for which 4 is a better CAI as compared to 5, whereas for the remaining ones (i.e., hCA III, IV, VA, VB, VI, VII, XIII and XIV), the difluoro substituted derivative $\mathbf{5}$ is a better inhibitor as compared to 4. This represents an indirect proof that the protonation state of the phenol moiety is not such a relevant parameter for the binding of the inhibitor within the enzyme cavity; (iii) clioquinol $\mathbf{6}$ is the most potent inhibitor among the three phenols investigated here, acting as a low micromolar inhibitor $\left(K_{\mathrm{I}} \mathrm{S}\right.$ in the range of 3.3 $16.0 \mu \mathrm{M})$ against all the investigated isozymes. Probably the bicyclic ring system and various heteroatoms (iodine, chlorine and nitrogen) present in $\mathbf{6}$ assures better hydrophobic interactions with amino acid residues in the hCA-6 complex as compared to the corresponding complexes of the monocyclic, less bulky derivatives $\mathbf{4}$ and $\mathbf{5}$, whereas the $\mathrm{OH}$ moiety of all these compounds is assumed to bind as depicted in Figure 1C; (iv) it should be noted that all three phenols $\mathbf{4} \mathbf{6}$ are generally orders of magnitude less effective CAIs as compared to the sulfonamides 1-3, except for isozyme hCA III, a sulfonamide resistant isoform, ${ }^{30}$ case in which the phenols are low micromolar (or even submicromolar inhibitors) whereas the sulfonamides 1-3 are millimolar inhibitors (Table 1). This is in fact the first time that so effective CA III inhibitors are detected, and it would be of great interest to resolve the X-ray crystal structure of a hCA III-phenol adduct in order to understand the structural basis for this higher affinity of these CAIs for this poorly understood CA isoform $;^{30}(\mathrm{v})$ there are important differences of affinity of the various CA isozymes for this class of CAI, similarly with what observed earlier for sulfonamide/sulfamate/sulfamide CAIs, ${ }^{2-6}$ or various classes of CA activators. ${ }^{25-29}$ This clearly demonstrates that (a) the phenol $\mathrm{OH}$ moiety can be considered as a new 'zinc-water binding group' for the design of CAIs possessing a different inhibition mechanism as compared to the classical inhibitors that bind the metal ion; and (b) by varying the ring system/scaffold and moieties substituting it, we hypothesize that much stronger, eventually nanomolar inhibitors belonging to this class can be detected, with potential to use as selective CAIs for various such enzymes with medicinal chemistry applications. For example, the present study and the X-ray data from Christianson's ${ }^{10}$ group allow us to speculate that phenols possessing a mono- or bicyclic aromatic/heterocyclic ring system, possibly substituted with various moieties in the 2-, 3-, and/or 4-positions of the benzene ring (as in derivatives $\mathbf{4}$ and $\mathbf{5}$, but with the option to incorporate bulkier moieties bound to the aromatic ring system) or in various positions of the bicyclic ring system (as in 6, but also with much more options regarding the number and the nature of the incorporated moieties as well as the substitution pattern) may lead to much more potent CAIs belonging to this class of derivatives. Work is in progress in our laboratory for the validation 
of this hypothesis and for resolving the X-ray crystal structure of some other CA-phenol complexes, such as for example the derivatives $\mathbf{5}$ and $\mathbf{6}$ investigated in the present study.

In conclusion, we investigated the binding of three phenols to the twelve mammalian, catalytically active CA isozymes. Phenol acts as an effective CA I-IV, IX, XII and XIV inhibitor $\left(K_{\mathrm{I}} \mathrm{s}\right.$ of $\left.2.7-11.5 \mu \mathrm{M}\right)$ and is less effective against the other isoforms, that is, CA VA, VB, VI, VII and XIII $\left(K_{\mathrm{I}} \mathrm{S}\right.$ of 208-710 $\left.\mu \mathrm{M}\right)$. 3,5-Difluorophenol is an effective inhibitor of CA III, IV, IX and XIV $\left(K_{\mathrm{I}} \mathrm{S}\right.$ of $\left.0.71-10.7 \mu \mathrm{M}\right)$ being a weaker one for CA I, II, VA, VB, VI, VII, XII and XIII ( $K_{\mathrm{I}} \mathrm{S}$ of $\left.33.9-163 \mu \mathrm{M}\right)$. Clioquinol (5-chloro-7-iodo-8-quinolinol) was the best inhibitor against all isozymes, with inhibition constants in the range of $3.3-16.0 \mu \mathrm{M}$. These data prove that the phenol $\mathrm{OH}$ moiety can be considered as a new 'zincwater binding group' for the design of CAIs possessing a different inhibition mechanism as compared to the classical sulfonamide inhibitors that bind the metal ion within the active site cavity.

\section{Acknowledgment}

This research was financed in part by two grants of the 6th Framework Programme of the European Union (EUROXY and DeZnIT projects).

\section{References and notes}

1. (a) Simonsson, I.; Jonsson, B. H.; Lindskog, S. Biochem. Biophys. Res. Commun. 1982, 108, 1406; (b) Tibell, L.; Forsman, C.; Simonsson, I.; Lindskog, S. Biochim. Biophys. Acta 1985, 829, 202.

2. (a) Supuran, C. T. Nat. Rev. Drug Discov., 2008, 7, in press.; (b) Thiry, A.; Dogné, J. M.; Masereel, B.; Supuran, C. T. Trends Pharmacol. Sci. 2006, 27, 566.

3. (a) Supuran, C. T.; Scozzafava, A.; Conway, J. Carbonic Anhydrase-Its Inhibitors and Activators; CRC Press: Boca Raton, New York, London, 2004, pp 1-363; (b) Köhler, K.; Hillebrecht, A.; Schulze Wischeler, J.; Innocenti, A.; Heine, A.; Supuran, C. T.; Klebe, G. Angew. Chem., Int. Ed. 2007, 46, 7697-7699.

4. (a) Pastorekova, S.; Parkkila, S.; Pastorek, J.; Supuran C. T. J. Enzyme Inhib. Med. Chem. 2004, 19, 199; (b) Supuran, C. T.; Scozzafava, A.; Casini, A. Development of sulfonamide carbonic anhydrase inhibitors. In Carbonic Anhydrase-Its Inhibitors and Activators; Supuran, C. T., Scozzafava, A., Conway, J., Eds.; CRC Press: Boca Raton, 2004; pp 67-147.

5. (a) Thiry, A.; Dogne, J. M.; Supuran, C. T.; Masereel, B. Curr. Top. Med. Chem. 2007, 7, 855; (b) Supuran, C. T.; Scozzafava, A.; Casini, A. Med. Res. Rev. 2003, 23, 146; (c) Scozzafava, A.; Mastrolorenzo, A.; Supuran, C. T. Expert Opin. Ther. Pat. 2006, 16, 1627.

6. (a) Supuran, C. T. Therapy 2007, 4, 355; (b) Supuran, C. T. Curr. Top. Med. Chem. 2007, 7, 825; (c) Supuran, C. T.; Scozzafava, A. Bioorg. Med. Chem. 2007, 15, 4336.

7. (a) Parkkila, S.; Parkkila, A. K.; Rajaniemi, H.; Shah, G. N.; Grubb, J. H.; Waheed, A.; Sly, W. S. Proc. Natl. Acad. Sci. U.S.A. 2001, 98, 1918; (b) Christianson, D. W.; Fierke, C. A. Acc. Chem. Res. 1996, 29, 331; (c) Nishimori, I. Acatalytic CAs: Carbonic Anhydrase-Related Proteins.
In Carbonic Anhydrase-Its Inhibitors and Activators; Supuran, C. T., Scozzafava, A., Conway, J., Eds.; CRC Press: Boca Raton, 2004; pp 25-43; (d) Lehtonen, J.; Shen, B.; Vihinen, M.; Casini, A.; Scozzafava, A.; Supuran, C. T.; Parkkila, A. K.; Saarnio, J.; Kivela, A. J.; Waheed, A.; Sly, W. S.; Parkkila, S. J. Biol. Chem. 2004, 279, 2719.

8. Briganti, F.; Mangani, S.; Scozzafava, A.; Vernaglione, G.; Supuran, C. T. J. Biol. Inorg. Chem. 1999, 4, 528.

9. Guerri, A.; Briganti, F.; Scozzafava, A.; Supuran, C. T.; Mangani, S. Biochemistry 2000, 39, 12391.

10. Nair, S. K.; Ludwig, P. A.; Christianson, D. W. J. Am. Chem. Soc. 1994, 116, 3659.

11. (a) Casini, A.; Antel, J.; Abbate, F.; Scozzafava, A.; David, S.; Waldeck, H.; Schäfer, S.; Supuran, C. T. Bioorg. Med. Chem. Lett. 2003, 13, 841; (b) De Simone, G.; Di Fiore, A.; Menchise, V.; Pedone, C.; Antel, J.; Casini, A.; Scozzafava, A.; Wurl, M.; Supuran, C. T. Bioorg. Med. Chem. Lett. 2005, 15, 2315.

12. (a) Nishimori, I.; Vullo, D.; Innocenti, A.; Scozzafava, A.; Mastrolorenzo, A.; Supuran, C. T. J. Med. Chem. 2005, 48, 7860; (b) Vullo, D.; Franchi, M.; Gallori, E.; Pastorek, J.; Scozzafava, A.; Pastorekova, S.; Supuran, C. T. Bioorg. Med. Chem. Lett. 2003, 13, 1005; (c) Winum, J. Y.; Dogne, J. M.; Casini, A.; de Leval, X.; Montero, J. L.; Scozzafava, A.; Vullo, D.; Innocenti, A.; Supuran, C. T. J. Med. Chem. 2005, 48, 2121.

13. (a) Vullo, D.; Innocenti, A.; Nishimori, I.; Pastorek, J.; Scozzafava, A.; Pastorekova, S.; Supuran, C. T. Bioorg. Med. Chem. Lett. 2005, 15, 963; (b) Nishimori, I.; Vullo, D.; Innocenti, A.; Scozzafava, A.; Mastrolorenzo, A.; Supuran, C. T. Bioorg. Med. Chem. Lett. 2005, 15, 3828.

14. (a) Nishimori, I.; Minakuchi, T.; Onishi, S.; Vullo, D.; Scozzafava, A.; Supuran, C. T. J. Med. Chem. 2007, 50, 381; (b) Vullo, D.; Voipio, J.; Innocenti, A.; Rivera, C.; Ranki, H.; Scozzafava, A.; Kaila, K.; Supuran, C. T. Bioorg. Med. Chem. Lett. 2005, 15, 971.

15. (a) Cecchi, A.; Hulikova, A.; Pastorek, J.; Pastorekova, S.; Scozzafava, A.; Winum, J.-Y.; Montero, J.-L.; Supuran, C. T. J. Med. Chem. 2005, 48, 4834.

16. (a) Schuster, R. J. Wien. Med. Wochenschr. 1959, 109, 1007; (b) Frye, W. W.; Lampert, R. Am. J. Gastroenterol. 1960, 34, 429; (c) Mett, H.; Gyr, K.; Zak, O.; Vosbeck, K. Antimicrob. Agents Chemother. 1984, 26, 35; (d) Soedin, K.; Syukran, O. K.; Fadillah, A.; Sidabutar, P. Pharmatherapeutica 1985, 4, 251.

17. Maibach, H. I. Arch. Dermatol. 1978, 114, 1773.

18. Bednarz-Prashad, A. J.; John, E. I. J. Infect. Dis. 1983, $148,613$.

19. (a) Shiraki, H. Jpn. J. Med. Sci. Biol. 1975, 28, 101; (b) Egashira, Y.; Matsuyama, H. Acta Pathol. Jpn. 1982, 32, 101; (c) Konagaya, M.; Matsumoto, A.; Takase, S.; Mizutani, T.; Sobue, G.; Konishi, T.; Hayabara, T.; Iwashita, H.; Ujihira, T.; Miyata, K.; Matsuoka, Y. J. Neurol. Sci. 2004, $218,85$.

20. (a) Helmuth, L. Science 2000, 290, 1273; (b) Regland, B.; Lehmann, W.; Abedini, I.; Blennow, K.; Jonsson, M.; Karlsson, I.; Sjögren, M.; Wallin, A.; Xilinas, M.; Gottfries, C. G. Dement. Geriatr. Cogn. Disord. 2001, 12, 408; (c) Melov, S. Trends Neurosci. 2002, 25, 121; (d) Ibach, B.; Haen, E.; Marienhagen, J.; Hajak, G. Pharmacopsychiatry 2005, 38, 178; (e) Crouch, P. J.; Barnham, K. J.; Bush, A. I.; White, A. R. Drug News Perspect. 2006, 19, 469.

21. (a) Nguyen, T.; Hamby, A.; Massa, S. M. Proc. Natl. Acad. Sci. U.S.A. 2005, 102, 11840; (b) Ferrada, E.; Arancibia, V.; Loeb, B.; Norambuena, E.; Olea-Azar, C.; Huidobro-Toro, J. P. Neurotoxicology 2007, 28, 445.

22. (a) Du, T.; Filiz, G.; Caragounis, A.; Crouch, P. J.; White, A. R. J. Pharmacol. Exp. Ther. 2008, 324, 360; (b) Chen, D.; Cui, Q. C.; Yang, H.; Barrea, R. A.; Sarkar, F. H.; 
Sheng, S.; Yan, B.; Reddy, G. P.; Dou, Q. P. Cancer Res. 2007, 67, 1636; (c) Choi, S. M.; Choi, K. O.; Park, Y. K.; Cho, H.; Yang, E. G.; Park, H. J. Biol. Chem. 2006, 281, 34056.

23. (a) Pastorekova, S.; Pastorek, J. Cancer-related carbonic anhydrase isozymes and their inhibition. In Carbonic Anhydrase-Its Inhibitors and Activators; Supuran, C. T., Scozzafava, A., Conway, J., Eds.; CRC Press: Boca Raton (FL), 2004; pp 255-281; (b) Semenza, G. L. Cancer Metastasis Rev. 2007, 26, 223.

24. Khalifah, R. G. J. Biol. Chem. 1971, 246, 2561, An SX.18MV-R Applied Photophysics (Oxford, UK) stopped-flow instrument has been used. Phenol red (at a concentration of $0.2 \mathrm{mM}$ ) has been used as indicator, working at the absorbance maximum of $557 \mathrm{~nm}$, with $10 \mathrm{mM}$ Hepes (pH 7.4) as buffer, $0.1 \mathrm{M} \mathrm{Na} \mathrm{SO}_{4}$ or $\mathrm{NaClO}_{4}$ (for maintaining constant the ionic strengththese anions are not inhibitory in the used concentration), ${ }^{12-15}$ following the CA-catalyzed $\mathrm{CO}_{2}$ hydration reaction for a period of 5-10 s. Saturated $\mathrm{CO}_{2}$ solutions in water at $25^{\circ} \mathrm{C}$ were used as substrate. Stock solutions of inhibitors were prepared at a concentration of $10 \mathrm{mM}$ (in DMSO-water $1: 1, \mathrm{v} / \mathrm{v}$ ) and dilutions up to $0.01 \mu \mathrm{M}$ done with the assay buffer mentioned above. Inhibitor and enzyme solutions were preincubated together for $10 \mathrm{~min}$ at room temperature prior to assay, in order to allow for the formation of the E-I complex. Triplicate experiments were done for each inhibitor concentration, and the values reported throughout the paper are the mean of such results. $K_{\mathrm{I}} \mathrm{s}$ were obtained from Lineweaver-Burk plots, as reported earlier. ${ }^{12-15}$
25. (a) Ilies, M.; Scozzafava, A.; Supuran, C. T. Carbonic anhydrase activators. In Carbonic Anhydrase-Its Inhibitors and Activators; Supuran, C. T., Scozzafava, A., Conway, J., Eds.; CRC Press: Boca Raton (FL), USA, 2004; pp 317-352; (b) Supuran, C. T.; Scozzafava, A. Activation of carbonic anhydrase isozymes. In The Carbonic Anhydrases-New Horizons; Chegwidden, W. R., Carter, N., Edwards, Y., Eds.; Birkhauser Verlag: Basel, Switzerland, 2000; pp 197-219.

26. (a) Temperini, C.; Scozzafava, A.; Vullo, D.; Supuran, C. T. Chemistry 2006, 12, 7057; (b) Temperini, C.; Scozzafava, A.; Vullo, D.; Supuran, C. T. J. Med. Chem. 2006, 49, 3019; (c) Temperini, C.; Scozzafava, A.; Puccetti, L.; Supuran, C. T. Bioorg. Med. Chem. Lett. 2005, 15, 5136.

27. (a) Temperini, C.; Scozzafava, A.; Supuran, C. T. Bioorg. Med. Chem. Lett. 2006, 16, 5152; (b) Temperini, C.; Innocenti, A.; Scozzafava, A.; Mastrolorenzo, A.; Supuran, C. T. Bioorg. Med. Chem. Lett. 2007, 17, 628.

28. (a) Parkkila, S.; Vullo, D.; Puccetti, L.; Parkkila, A. K.; Scozzafava, A.; Supuran, C. T. Bioorg. Med. Chem. Lett. 2006, 16, 3955; (b) Vullo, D.; Nishimori, I.; Innocenti, A.; Scozzafava, A.; Supuran, C. T. Bioorg. Med. Chem. Lett. 2007, 17, 1336.

29. (a) Vullo, D.; Innocenti, A.; Nishimori, I.; Scozzafava, A.; Kaila, K.; Supuran, C. T. Bioorg. Med. Chem. Lett. 2007, 17, 4107; (b) Nishimori, I.; Onishi, S.; Vullo, D.; Innocenti, A.; Scozzafava, A.; Supuran, C. T. Bioorg. Med. Chem. 2007, 15, 5351.

30. Nishimori, I.; Minakuchi, T.; Onishi, S.; Vullo, D.; Cecchi, A.; Scozzafava, A.; Supuran, C. T. Bioorg. Med. Chem. 2007, 15, 7229. 